\title{
UCRL-TR-208589
}

LAW RENCE LIVERMORE N A T IO N A L LABORATORY

L. L. Hsiung

\author{
December 14, 2004
}

Low-Temperature Aging Mechanisms in U-6wt\% Nb 
This document was prepared as an account of work sponsored by an agency of the United States Government. Neither the United States Government nor the University of California nor any of their employees, makes any warranty, express or implied, or assumes any legal liability or responsibility for the accuracy, completeness, or usefulness of any information, apparatus, product, or process disclosed, or represents that its use would not infringe privately owned rights. Reference herein to any specific commercial product, process, or service by trade name, trademark, manufacturer, or otherwise, does not necessarily constitute or imply its endorsement, recommendation, or favoring by the United States Government or the University of California. The views and opinions of authors expressed herein do not necessarily state or reflect those of the United States Government or the University of California, and shall not be used for advertising or product endorsement purposes.

This work was performed under the auspices of the U.S. Department of Energy by University of California, Lawrence Livermore National Laboratory under Contract W-7405-Eng-48. 


\section{LOW-TEMPERATURE AGING MECHANISMS IN U-6wt\% Nb}

Luke L. Hsiung

Materials Science and Technology Division

L-352

\section{Objectives and Accomplishments}

Phase stability and aging mechanisms in a water-quenched (WQ) U-6wt\% Nb (U-14at\% Nb) alloy artificially aged at $200^{\circ} \mathrm{C}$ and naturally aged at ambient temperature for 15 years have been investigated and studied using Vickers-hardness measurement, X-ray diffraction (XRD) analysis, and transmission electron microscopy (TEM) techniques. Age hardening/softening phenomenon is recorded from the artificially aged samples based upon the microhardness measurement. The age hardening can be readily rationalized by the occurrence of fine-scaled Nb segregation, or spinodal decomposition, within the $\alpha^{\prime \prime}$ domains, which results in the formation of a modulated structure containing nano-scaled Nb-rich and Nb-lean domains. Prolonged aging leads to age softening of the alloy by coarsening of the modulated structure. Chemical ordering, or disorder-order phase transformation, is found within the naturally aged alloy according to TEM observations of antiphase domain boundaries (APBs) and superlattice diffraction patterns. A possible superlattice structure for the ordered $\alpha^{\prime \prime}$ phase observed in the naturally aged sample and underlying low-temperature aging mechanisms are proposed.

\section{$\underline{\text { Introduction }}$}

It is well known that U-6wt. \%Nb (U6Nb hereafter) or U-14 at. \%Nb alloy as exploited for a variety of engineering applications has a microstructure containing martensitic phases supersaturated with $\mathrm{Nb}$, which can be obtained by rapid quenching the alloy from $\gamma$ (bcc)-field solid solution to room temperature [1, 2]. The high cooling rate forces the $\gamma$-phase solid solution to transform martensitically to a variant of the low temperature $\alpha$ (orthorhombic) phase in which $\mathrm{Nb}$ is retained in supersaturated solid solution. Because the variant phase is supersaturated and its lattice parameters differ from the equilibrium $\alpha$ phase, it has been designated $\alpha^{\prime}$ martensite. Two additional variant phases, a monoclinic distortion of $\alpha^{\prime}$, named $\alpha^{\prime \prime}$ martensite, or a tetragonal distortion of $\gamma$, named $\gamma^{0}$ martensite, can also be formed within the as-quenched material. The resulting alloy has improved mechanical properties (ductility and toughness) and excellent corrosion resistance because of the uniform distribution of $\mathrm{Nb}$ in solid solution that suppresses the diffusional decomposition reaction to form two-phase (an $\alpha$ phase and a Nb-enriched $\gamma$ phase) cellular microstructures, which are undesirable for engineering applications.

It has been reported that the water-quenched (WQ) U6Nb alloy containing extensively twinned $\alpha^{\prime \prime}$ martensitic microstructure results in low yield strength ( 200 MPa) and high tensile ductility ( 30\%) [2]. It has also been demonstrated that the U-Nb alloy containing $\alpha^{\prime \prime}$ martensite reveals shape memory effect [3], and the shape memory behavior is controlled mainly by the twin structures within the alloy [4]. Aging of the $\alpha^{\prime \prime}$ martensite in the $150^{\circ} \mathrm{C}$ to $400^{\circ} \mathrm{C}$ range results in increase of yield strength to as high as 1.3 GPa due to very fine scale microstructural changes [5], which have not yet been fully characterized but may have involved spinodal decomposition. Over-aging occurs at temperatures above $400^{\circ} \mathrm{C}$, where cellular decomposition occurs to form coarse two-phase cellular microstructures. The occurrence of these decompositions in association with $\mathrm{Nb}$ segregation can subsequently deteriorate and embrittle the alloys by reducing ductility and toughness as well as corrosion resistance [2,5]. Therefore, it is necessary to investigate and understand the aging effects on the microstructural and phase stability of WQ-U6Nb alloy. The investigation of aging effects on WQ-U6Nb reported in the open literature up to present has mainly been placed on aging at temperatures above $400^{\circ} \mathrm{C}$. Relatively little is known 
about the aging mechanism of WQ-U6Nb below $400^{\circ} \mathrm{C}$, the only detailed investigation of segregation reaction within isothermally aged WQ-U6Nb below $400^{\circ} \mathrm{C}$ was reported by Beverini and Edmonds [6], who have investigated the low-temperature aging behavior using Vickers hardness measurement and Atom Probe Field Ion Microscopy (APFIM) methods. According to their results, an age hardening/softening phenomena associated with nanometer length-scale of segregation reaction, possibly spinodal decomposition, was detected within the aged alloy samples. Figure 1 shows the effect of aging time at various temperatures on Vickers hardness. Figure 2 shows a section of a composition profile obtained from random area APFIM analysis performed on a sample aged at $300^{\circ} \mathrm{C}$ for 16 hours. A non-random Nb fluctuation is observed. The wave-length of composition fluctuation is of the order of $3 \mathrm{~nm}$. It is noted that the spinodal decomposition is a continuous clustering mechanism in which the supersaturated solid solution separates spontaneously into solute-lean and solute-rich phases within the parent phase domain through uphill diffusion, which is totally different from the nucleation and growth mechanism via downhill diffusion as illustrated in Fig. 3 [7]. In order to further elucidate the lowtemperature aging mechanisms, our investigation was accordingly focused on the microstructure and phase stability of the WQ-U6Nb alloy during isothermal aging below $200^{\circ} \mathrm{C}$.

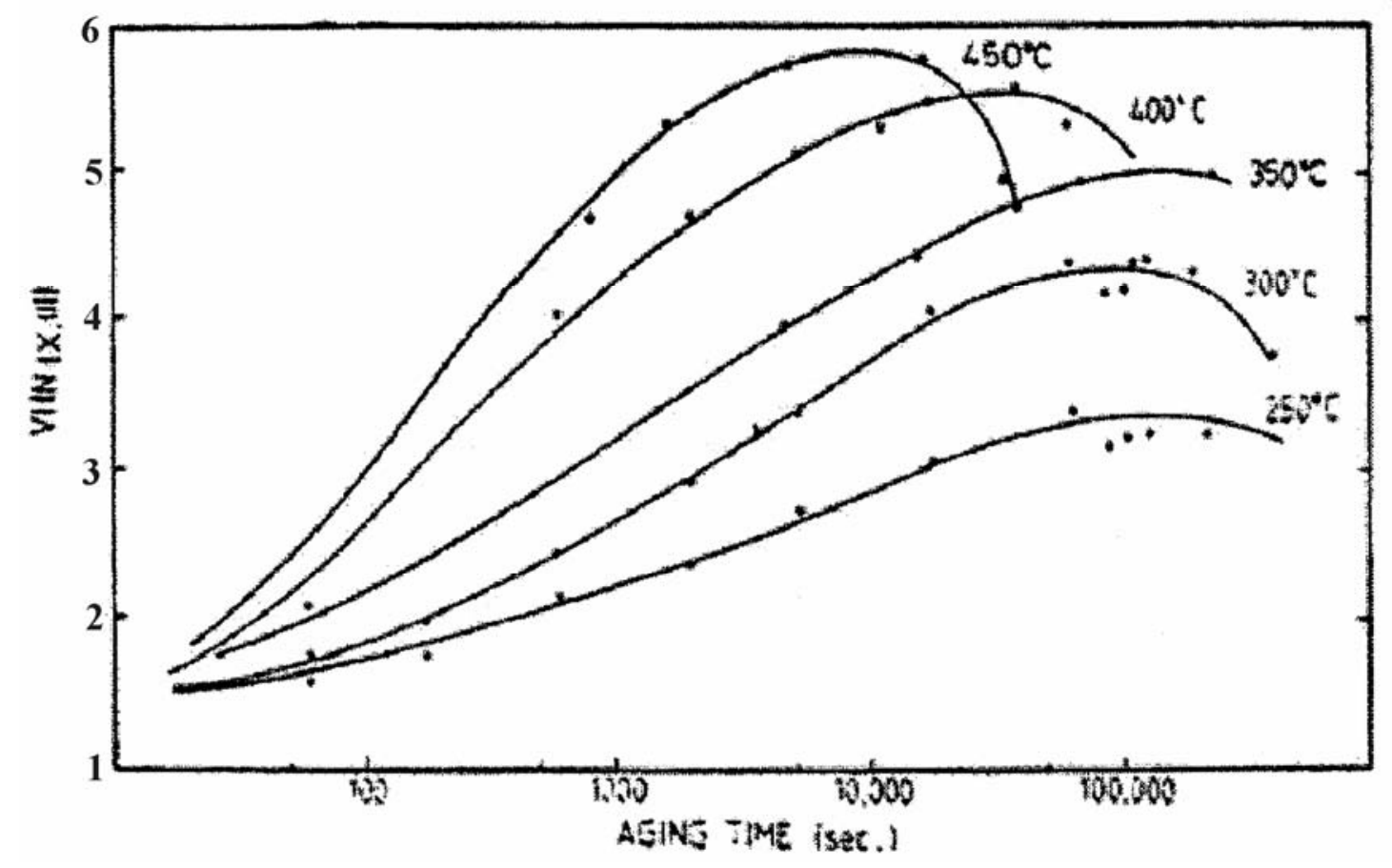

Fig. 1. Aging behavior of U-6Nb occurred at temperatures ranging between $250^{\circ} \mathrm{C}$ and $450^{\circ} \mathrm{C}$ [6]. 


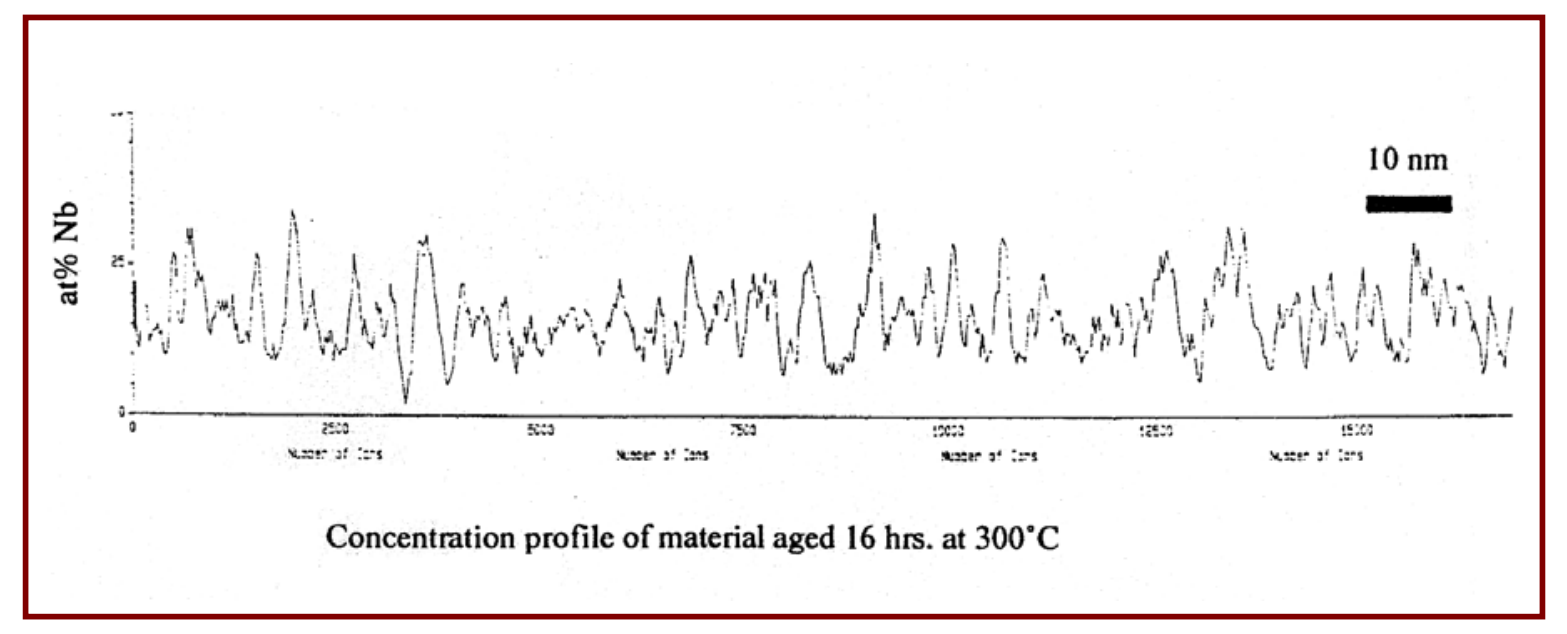

Fig. 2. APFIM concentration profile of a sample aged at $300^{\circ} \mathrm{C}$ for 16 hours [6].

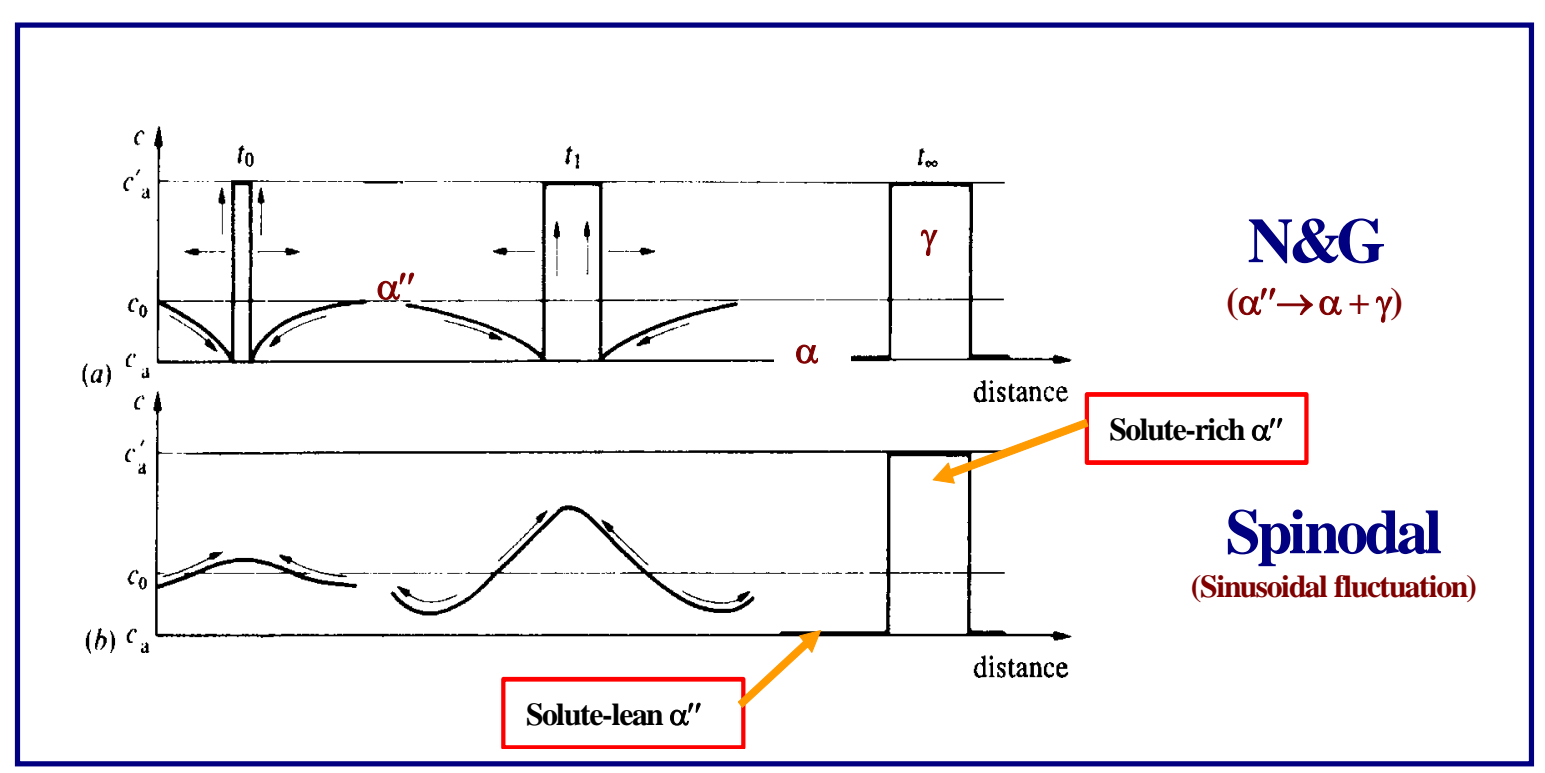

Fig. 3. Decomposition mechanisms: nucleation and growth (N\&G) versus spinodal decomposition, in which spatial variation in solute distribution during (a) a nucleation and growth reaction, and (b) a continuous spinodal reaction at the beginning (time $t_{0}$ ) and toward the end $\left(\mathrm{t}_{\infty}\right)$ of the decomposition reaction [7].

\section{$\underline{\text { Approach }}$}

The U6Nb alloy used for this investigation was wrought processed from Rocky Flats VAR VAR ingot at the BWXT/Bechtel Y-12 plant. Detailed information regarding the fabrication process can be found in [2]. Nb contents (in wt\%) analyzed from different locations of the ingot were 5.79 (bottom edge), 5.97 (top edge), 6.03 (bottom center), and 6.10 (Top center). Five rod-shape samples of $3 \mathrm{~mm}$ in diameter were machined from a wrought-processed $38 \mathrm{~mm}$ thick plate. Each of these five samples was then encapsulated in a Cu tube and was solution treated at $800^{\circ} \mathrm{C}$ for 4 hours followed by water quench. One of the water-quenched samples was examined and characterized under as water-quenched condition (designated as WQ). The remaining four of the water-quenched samples were artificially aged at $200^{\circ} \mathrm{C}$ for 2 hours (designated as 2h), 4 hours (4h), 8 hours (8h), and 16 hours (16h). Sample NA was designated to a naturally aged sample obtained from a 15-year old alloy sample. X-ray diffraction 
analysis was conducted with all the samples using a Philips XRG diffractometer with $\mathrm{Cu}(\mathrm{K} \alpha)$ radiation $(\lambda=1.5406 \AA)$. The employed scanning angles $(2 \theta)$ for diffraction ranged from $20^{\circ}$ to $80^{\circ}$ with a scanning rate of $2^{\circ} \mathrm{min}^{-1}$. Microhardness measurements were performed on all these samples using a Vickers-hardness indenter. The applied load was $50 \mathrm{~g}$ and the time duration is $35 \mathrm{sec}$ for each test. To obtain a statistically significant value, six tests were conducted for each measurement. Microstructures of the WQ, the artificially aged, and the NA samples were examined using a JEOL 200CX transmission electron microscope (TEM). TEM foils were machined from the rod-shape samples and the finial thinning of the foils was prepared by twinjet electropolishing in a solution of $45 \mathrm{vol} \%$ methanol, 45 vol\% butyl alcohol and 10 vol\% nitric acid at $50 \mathrm{~V}$ and $-20^{\circ} \mathrm{C}$.

\section{$\underline{\text { Results }}$}

\section{Artificial aging at $200^{\circ} \mathrm{C}$}

Figure 4 shows the results obtained from Vickers-hardness measurement, XRD analysis, and TEM observation of WQ and artificially aged (2h, 4h, 8h, and 16h) samples. A significant change in hardness is obtained from the artificially aged samples, which can be readily seen in Fig. 4(a). The hardness initially increases from HV $190.0 \pm 5.8$ for the WQ sample to HV $237.0 \pm 6.4$ and $254.8 \pm 12.2$ for the $4 \mathrm{~h}$ and $8 \mathrm{~h}$ samples respectively and then decreases to HV $237.3 \pm 10.0$ for the $16 \mathrm{~h}$ sample. The age hardening/softening phenomenon observed in Fig. 4(a) is consistent with the result previously shown in Fig. 2, and it cannot be satisfactorily interpreted by a change of microstructural morphology or phase content caused by long-range diffusion. As can be seen from the XRD and TEM results shown in Figs. 4(b) and 4(c), both WQ and artificially aged samples contain mainly the heavily twinned $\alpha^{\prime \prime}$ phase, and the morphological change is insignificant. However, the hardening/softening phenomenon can be well interpreted by the occurrence of spinodal decomposition resulted from short-range diffusion, which leads to the formation of a modulated structure shown in Figs. 5(a) - 5(d). It is noted that the fine-scale modulated structure caused by spinodal decomposition generally appeared as dark/bright fringes in TEM image accompanied by the appearance of satellite (or side) spots around the Bragg spots of the diffraction pattern [8,9]. A modulated structure, which presumably contains very fine domains $(\sim 3 \mathrm{~nm}$ in size) of Nb-lean and Nb-rich phases resulted from spinodal decomposition, was first observed at a local region within the $2 \mathrm{~h}$ sample [Fig. 5(a)]. It became more pronounced and to cover a larger portion of the $4 \mathrm{~h}$ and $8 \mathrm{~h}$ sample [Figs. 5(b) and (c)], which causes the hardness to increase to a maximum. Further aging causes the coarsening of the modulated structure to occur, which subsequently leads to a decrease in hardness. As can be clearly seen in Fig. 5(c), an increase of domain width to 45 nm was observed within the $16 \mathrm{~h}$ sample. Since the change of segregated phase-domains can affect the mobility of dislocation motion during deformation, it influences the hardness (strength) of artificially aged samples.

In summary, we have so far revealed an insignificant change in the phase content and microstructural morphology of alloy samples artificially aged at $200^{\circ} \mathrm{C}$ but detected the formation of nano-scale modulated structure within the alloy samples. The forming and coarsening of modulated domains result in the occurrence of age hardening/softening behavior according to the microhardness measurement. Previous work has shown significant changes in mechanical properties as a result of the composition modulations produced by spinodal decomposition $[6,9,10]$.

\section{Natural aging at ambient temperature}

Similar to the artificially aged samples, the change of microstructural morphology within the 15year NA sample, which contains mainly the heavily twinned $\alpha^{\prime \prime}$ domains, is insignificantly 
noticeable. However, a very interesting finding within the NA sample is the formation of swirlshape antiphase domain boundaries (APBs) as shown in Fig. 6. It is worthy to note that the contrast of antiphase domain boundary (also known as $\pi$ boundary) is visible when the phase angle $\alpha=$ $2 \pi$ g.P $=\pi$ and is invisible when $\alpha=2 \pi$ (where $\mathbf{g}$ is the reflection vector for imaging, and $\mathbf{P}$ is the displacement vector of APB) [11]. The observation of APBs reveals the occurrence of a disorderorder transformation, which results in the formation of chemically ordered domains within the NA sample. In essence, the ordered phase domain has the same crystal structure as that of the disordered phase domain, except it takes up a superlattice arrangement because of the periodic occupation of lattice sites by specific atom species. Accordingly, new chemically ordered $\alpha^{\prime \prime}$ phase is proposed and its structure is identified by a comparison between observed and simulated diffraction patterns. The illustrations of two possible schemes for the disorder-order transformation in $\alpha^{\prime \prime}$ phase are illustrated in Fig. 7. For the ordering transformation of Scheme I, U atoms occupy the following three specific lattice sites of the ordered superlattice (4 lattice sites/unit cell): (0,5/6,1/2), $(1 / 2,1 / 3,1 / 2)$, and $(1 / 2,1 / 2,0)$, whereas the $(0,0,0)$ lattice site is randomly occupied by $\mathrm{U}$ and $\mathrm{Nb}$ atoms, in which the probability of the site occupied by $\mathrm{U}$ and $\mathrm{Nb}$ are $44 \%$ and $56 \%$, respectively. For the ordering transformation of Scheme II, $U$ atoms occupy $(0,5 / 6,1 / 2)$ and $(1 / 2,1 / 3,1 / 2)$ lattice sites, whereas the $(0,0,0)$ and $(1 / 2,1 / 2,0)$ lattice sites are randomly occupied by $U$ and $\mathrm{Nb}$ atoms, in which the probability of the sites occupied by $\mathrm{U}$ and $\mathrm{Nb}$ are $72 \%$ and $28 \%$, respectively. The systematic variations in the atomic positions result in different ordered-domains separated by APBs across which the atoms have the wrong immediate neighbors, which is illustrated in Fig. 7(a). It is also noted that the Scheme II ordering transformation as illustrated in Fig. 7(b) may also be considered as a spinodal decomposition with the wave-length $(\lambda)$ of composition fluctuation that is equal to the lattice parameter of $\alpha^{\prime \prime}$ unit cell in the z-direction, i.e. $\lambda=c=0.495 \mathrm{~nm}$, which is approximately an order smaller than that observed within samples artificially aged at $200^{\circ} \mathrm{C}$.

The [110]-, [310]-, [312]-, and [100]-zone selected-area diffraction patterns generated from the 15-year NA sample are shown in Figs. 8 and 9, in which the corresponding zone diffraction patterns simulated according to the Schemes I and II ordering transformations are also displayed. It is noted that the simulation patterns of the [110]-, [310]-, and [312]-zone are identical between Scheme I and II as shown in Fig. 8, whereas the simulation patterns of the [001]-zone are different between Scheme I and II as shown in Fig. 9. The ordering transformation of $\alpha^{\prime \prime}$ phase is identified to be most likely of Scheme II type in accordance to the observed and simulated [100]-zone patterns as shown in Fig. 6. A typical g.P image-contrast analysis for APBs in a 15-year NA sample is shown in Fig. 10, where the APBs are visible using (00다) and $(0 \overline{2} \overline{1})$ superlattice reflections but become invisible when using a $(0 \overline{2} 0)$ fundamental reflection to image.

\section{Proposed Aging pathways}

Based upon the results discussed and shown above, low-temperature aging mechanisms and transformation pathways for WQ-U6Nb are accordingly proposed and illustrated with a hypothetical free energy-composition diagram shown in Fig. 11. At temperatures above a critical temperature $\left(T_{0}\right)$, because of a relatively higher diffusivity, the disordered $\alpha^{\prime \prime}$ initially undergoes spinodal decomposition and subsequently follows an ordering transformation, i.e. $\alpha^{\prime \prime} \rightarrow \alpha$ (Nb-lean) $+\alpha^{\prime \prime}$ (Nb-rich) $\rightarrow \alpha$ (disordered) $+\alpha^{\prime \prime}$ (ordered). At temperatures below the critical temperature, because of a more sluggish diffusivity, the disordered $\alpha^{\prime \prime}$ phase first undergoes an ordering transformation and subsequently spinodal decomposition follows i.e. $\alpha^{\prime \prime} \rightarrow \alpha^{\prime \prime}$ (partially ordered) $\rightarrow \alpha$ (disordered) $+\alpha^{\prime \prime}$ (ordered). In essence a fully ordered $\alpha^{\prime \prime}\left(\mathrm{U}_{\mathrm{x}} \mathrm{Nb}_{\mathrm{y}}\right)$ phase (precipitate) is suggested to form within extensively aged U6Nb at low temperatures. To understand the influence of the formation of fully 
ordered $\alpha^{\prime \prime}$ precipitates on the tensile ductility of naturally aged alloy, accelerated aging experiments have been conducted by aging the 15-yr stockpile-returned samples at temperatures below $200^{\circ} \mathrm{C}$. Preliminary results generated from TEM and tensile testing have indicated that the occurrence of ordering transformation and the formation of ordered precipitates will significantly influence the ductility of the alloy.

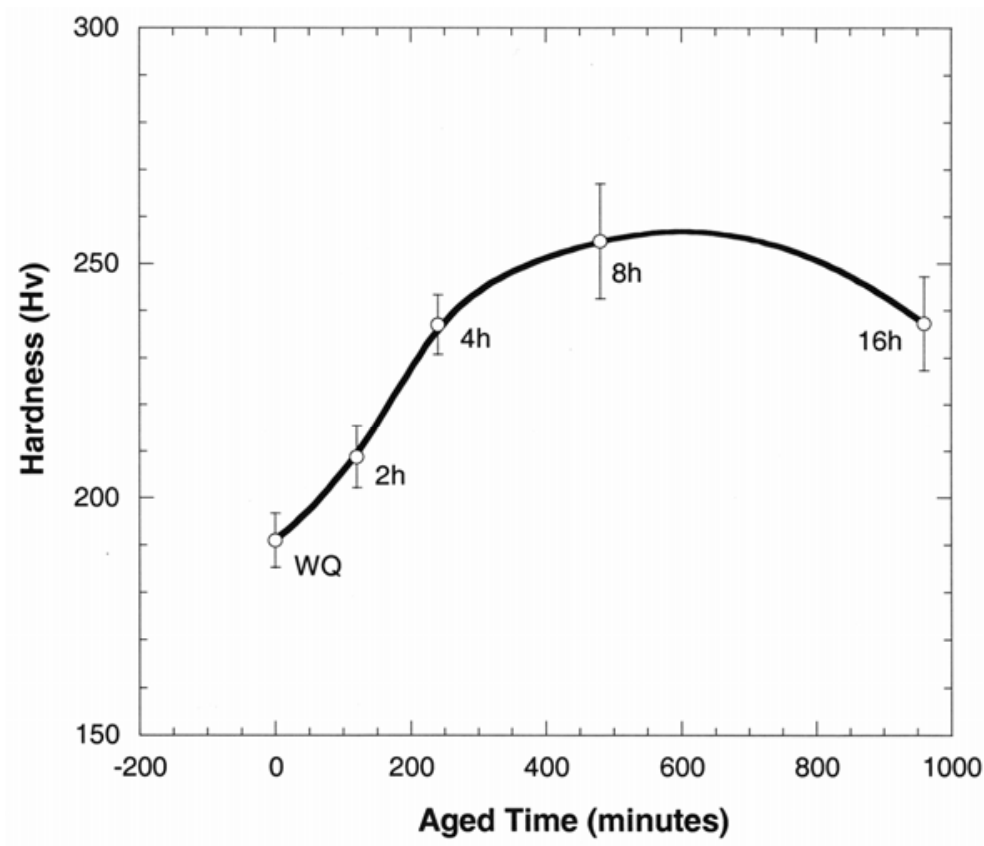

(a)
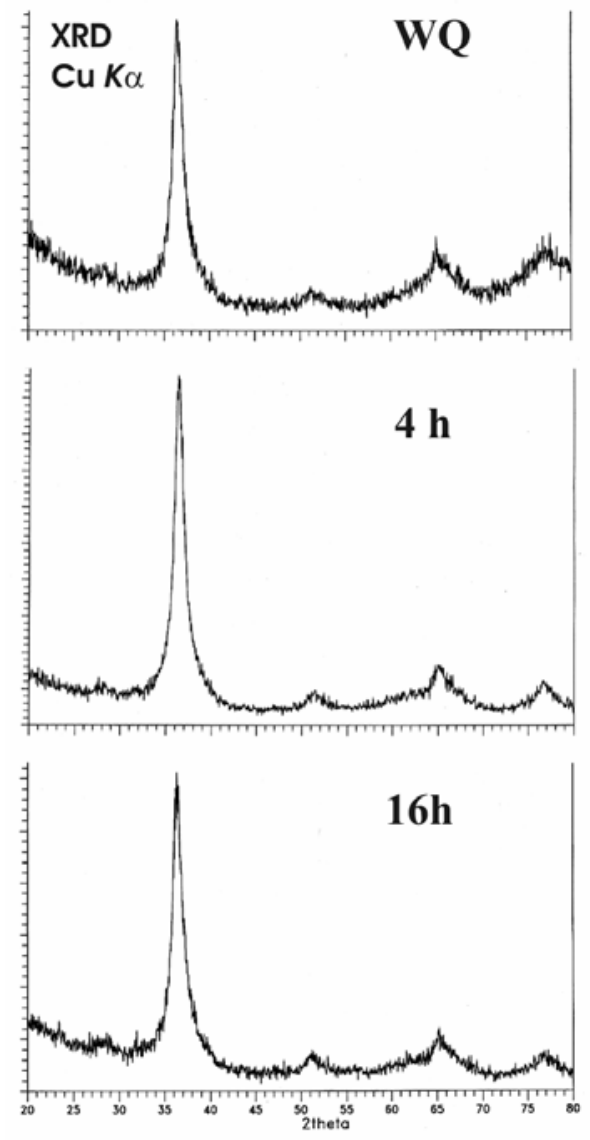

(b)
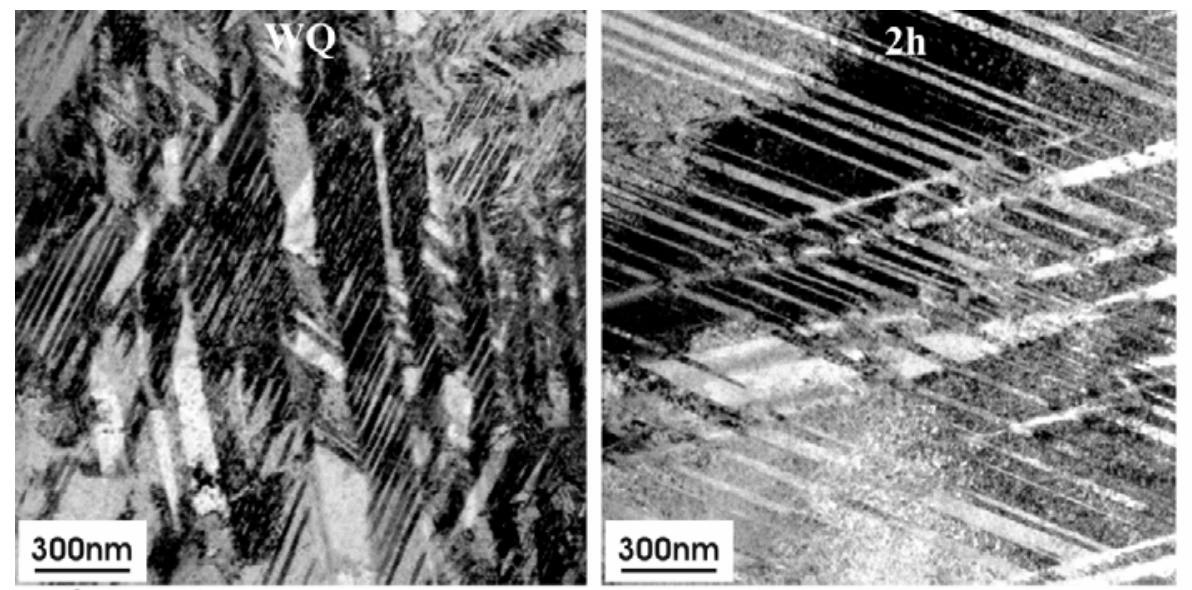

(c)

Fig. 4. Results of microhardness measurement, XRD analysis, and TEM characterization obtained from water-quenched and artificially aged alloy samples. 

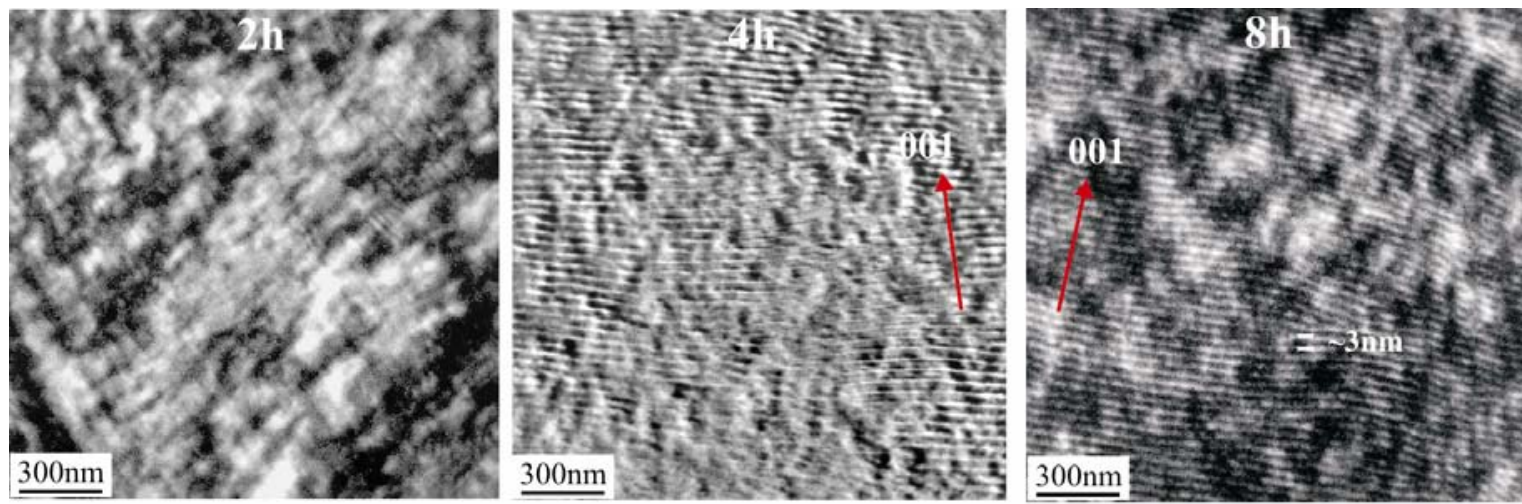

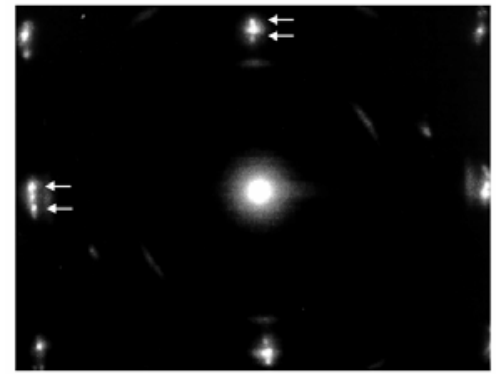

(a)

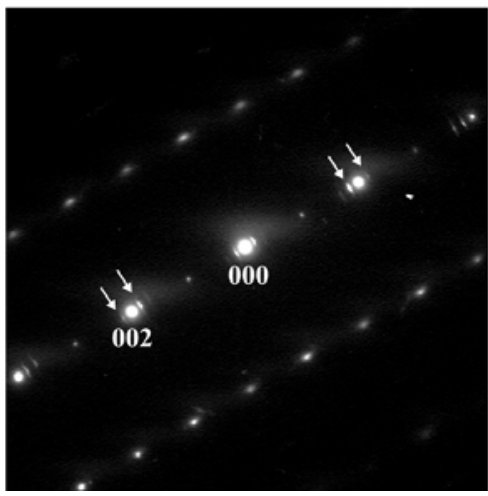

(b)

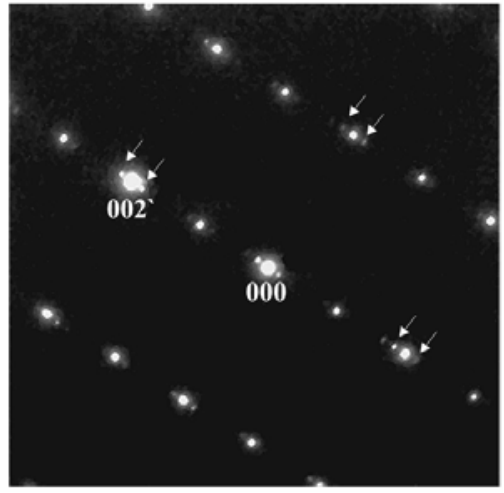

(c)
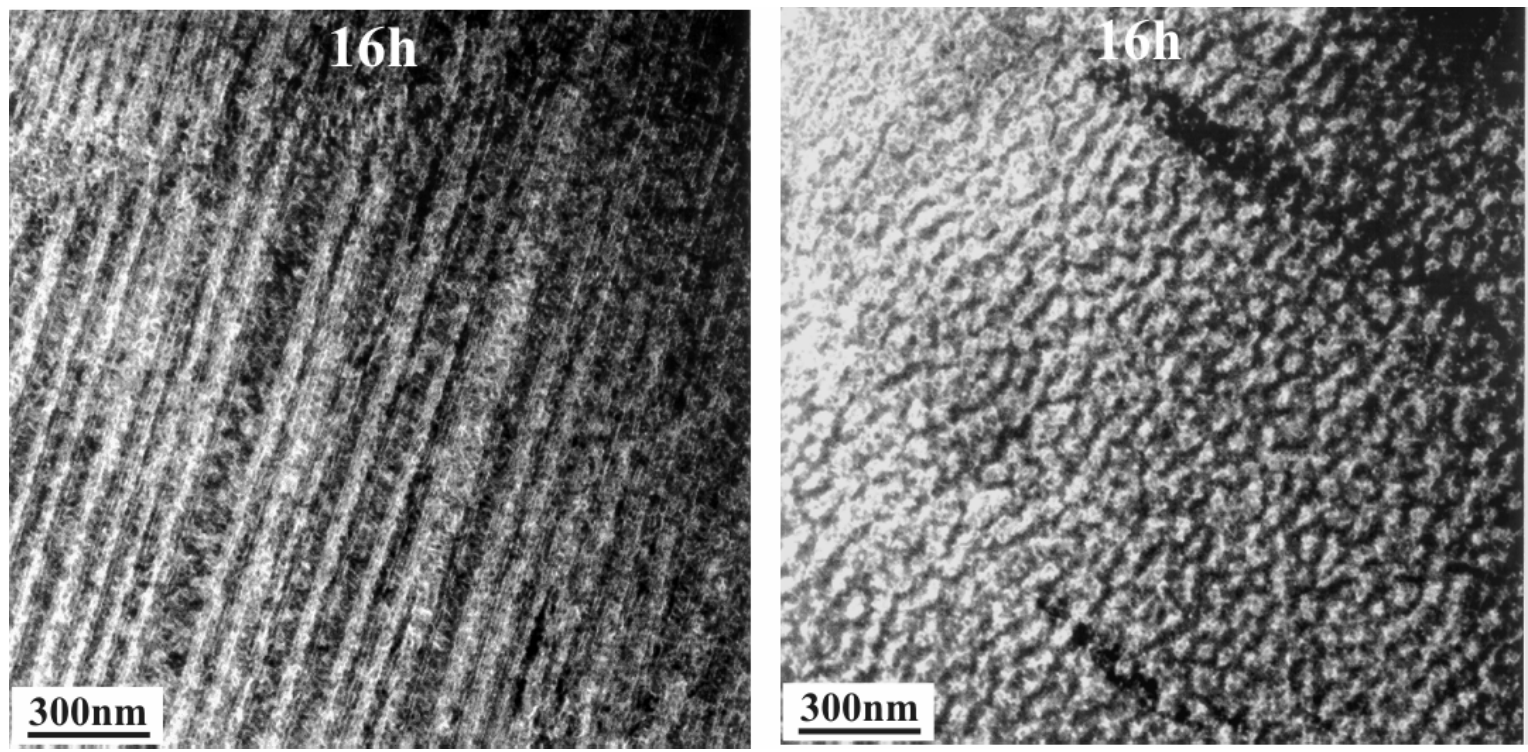

(d)

Fig. 5. TEM images and selected-area diffraction (SAD) patterns showing the formation of modulated structures within the artificially aged $2 \mathrm{~h}, 4 \mathrm{~h}, 8 \mathrm{~h}$ and $16 \mathrm{~h}$ samples. Satellite (Side) spots caused by the modulation are arrowed in SAD patterns shown in (a), (b), and (c). Coarsening of the modulation observed in 16h sample is shown in (d). 


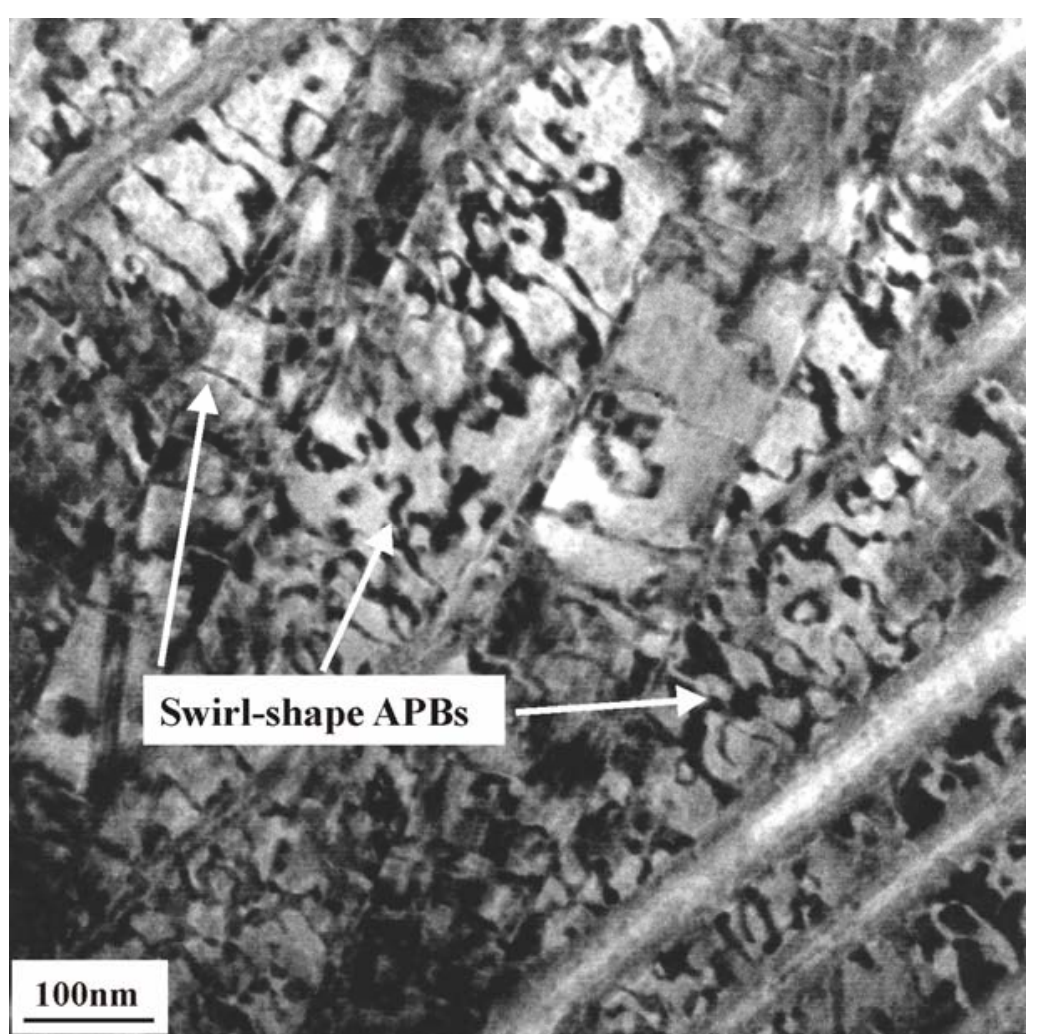

(a)

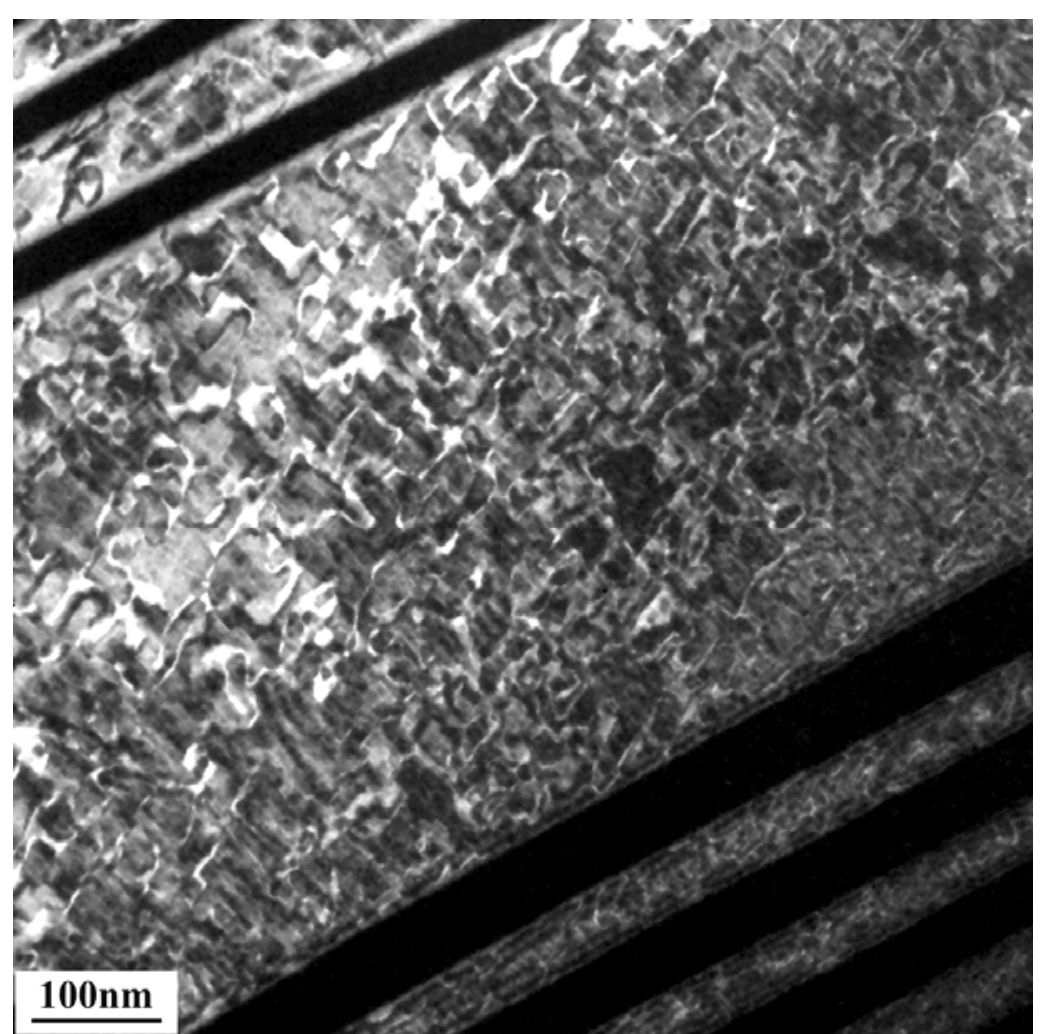

(b)

Fig. 6. Bright-field (a) and dark-field (b) TEM images reveal the formation of swirl-shape antiphase domain boundaries (APBs) within the 15-year NA sample. Notice that APBs appear as a dark contract in (a) and a bright contrast in (b). 
(a)
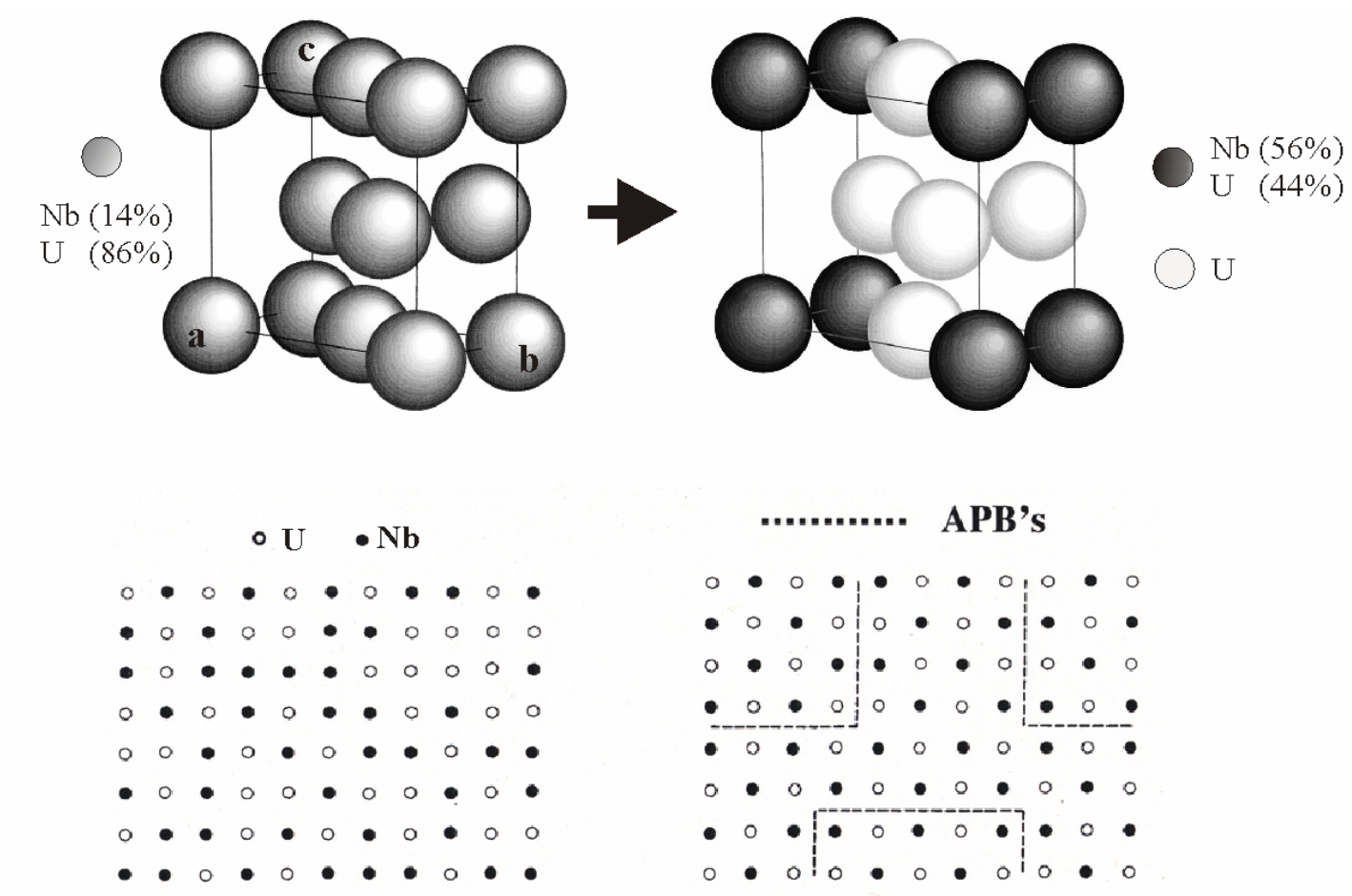

Disorder

Order

(b)
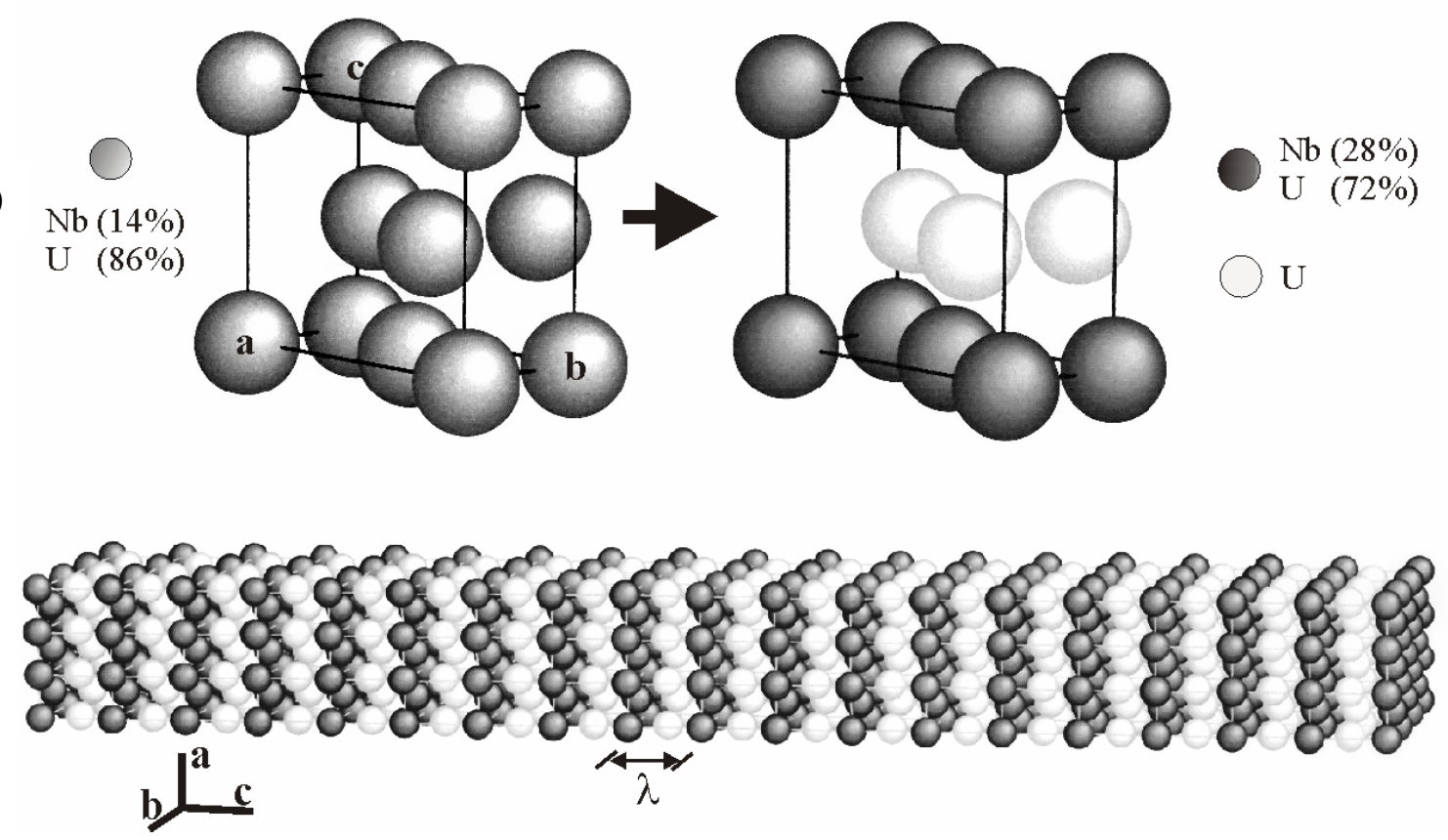

Fig. 7. Schematic illustrations showing two possible schemes proposed for the disorder-order transformation occurred in the binary U-14at\%Nb (U-6wt\%Nb) alloy, in which two different partially ordered $\alpha^{\prime \prime}$ unit cells can be generated according to (a) Scheme I. and (b) Scheme II ordering transformations. 


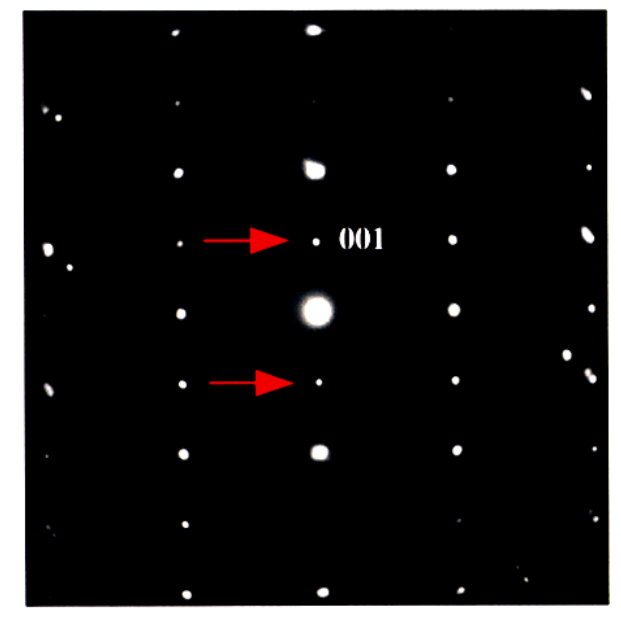

[110]

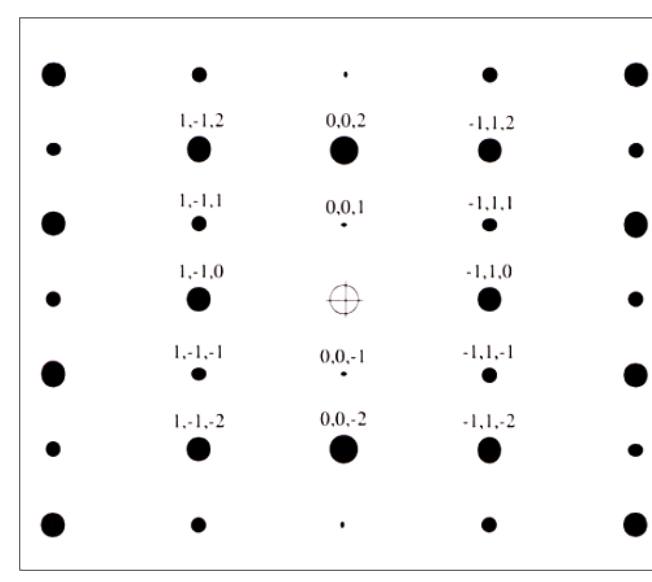

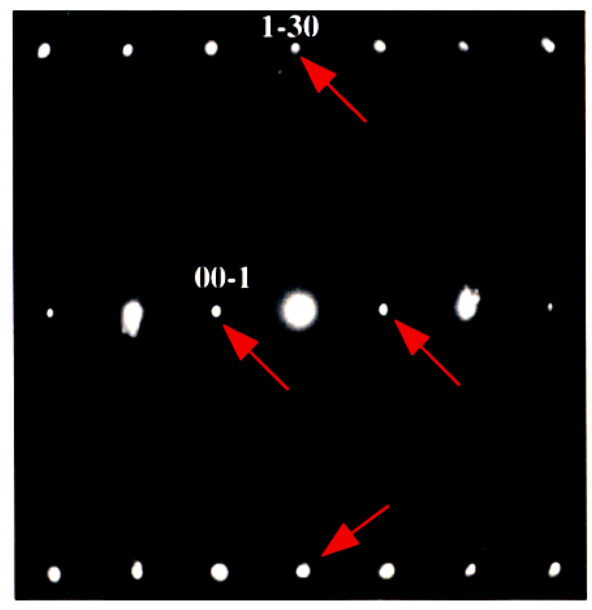

[310]

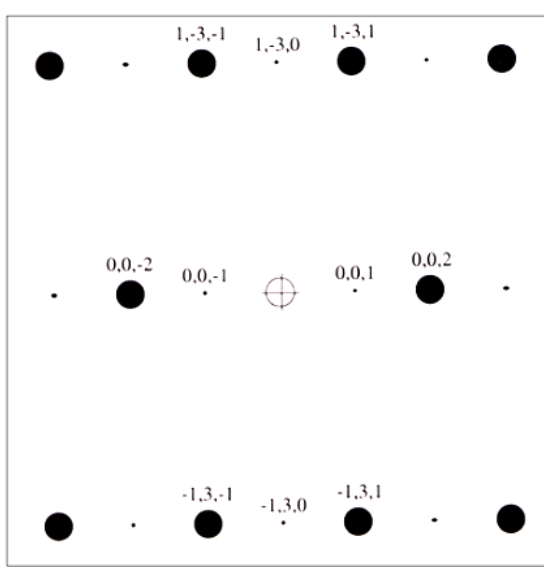

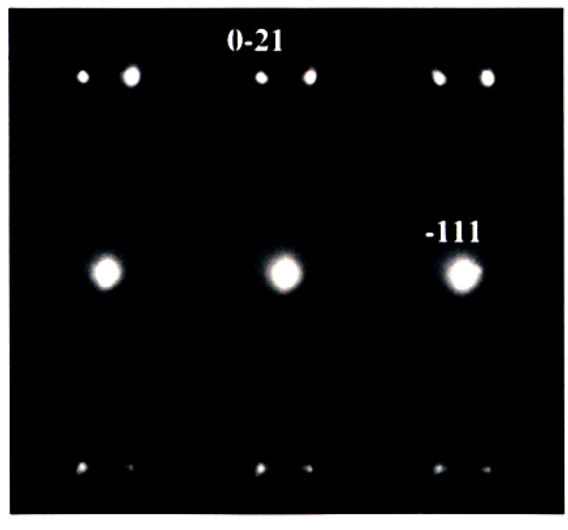

[312]

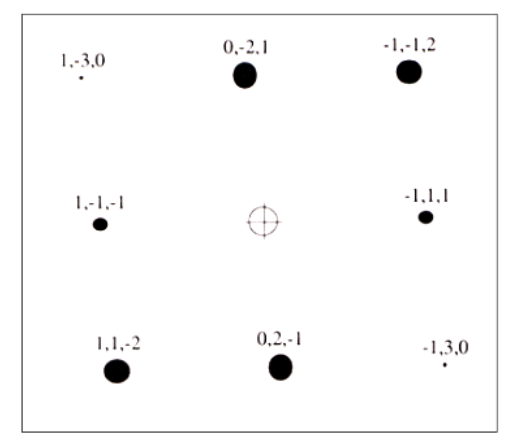

Fig. 8. The [110]-, [310]-, and [312]-zone diffraction patterns generated from the 15-year NA sample, in which the superlattice spots are arrowed (upper). Note that the [312]-zone diffraction pattern includes the diffraction spots generated from twin domains. The corresponding zone diffraction patterns simulated for the proposed ordered $\alpha^{\prime \prime}$ unit cell according to Schemes I and II ordering transformations are shown below. 


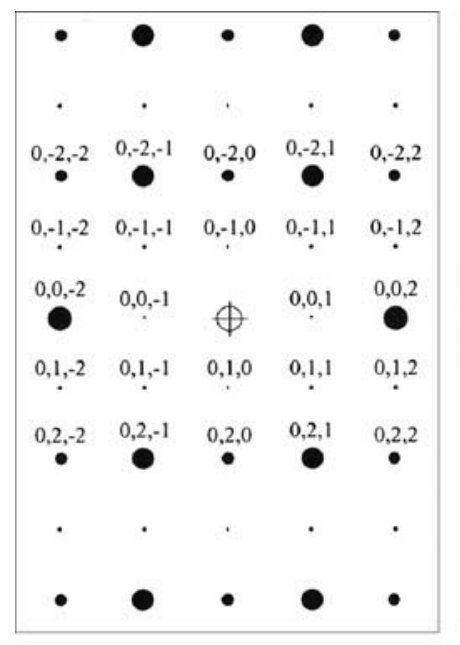

Scheme I

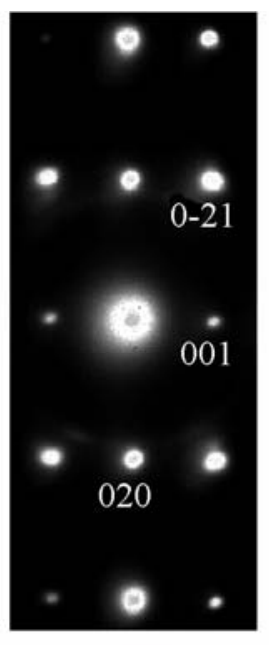

[100]

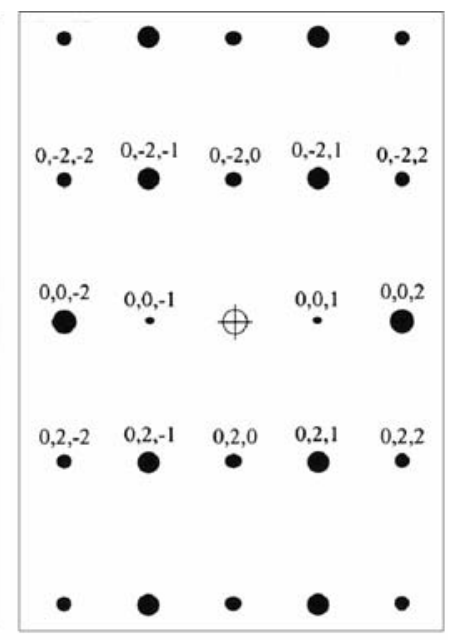

Scheme II

Fig. 9. The [100]-zone diffraction pattern generated from 15-yr NA sample shown with simulated patterns based upon Scheme I and II unit cells. Scheme II is more likely to be the one for the partially ordered $\alpha^{\prime \prime}$ phase according to the comparison between observed and simulated patterns.

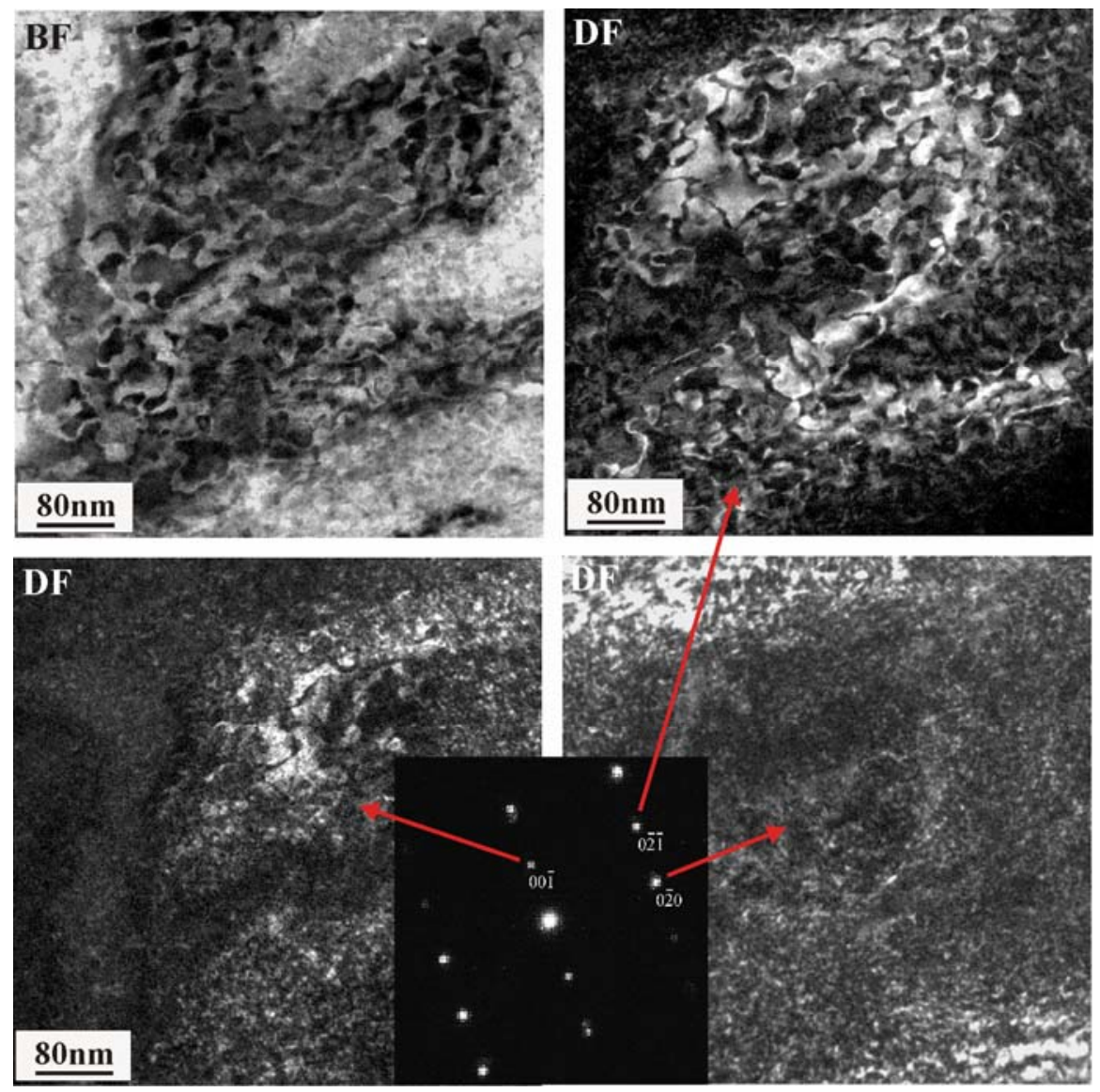

Fig. 10. BF and DF images of growth APBs in an ordered $\alpha^{\prime \prime}$ domain observed in the same area. The APBs are visible using $(00 \overline{1})$ and $(0 \overline{2} \overline{1})$ superlattice reflections but become invisible using a $(0 \overline{2} 0)$ fundamental reflection. 


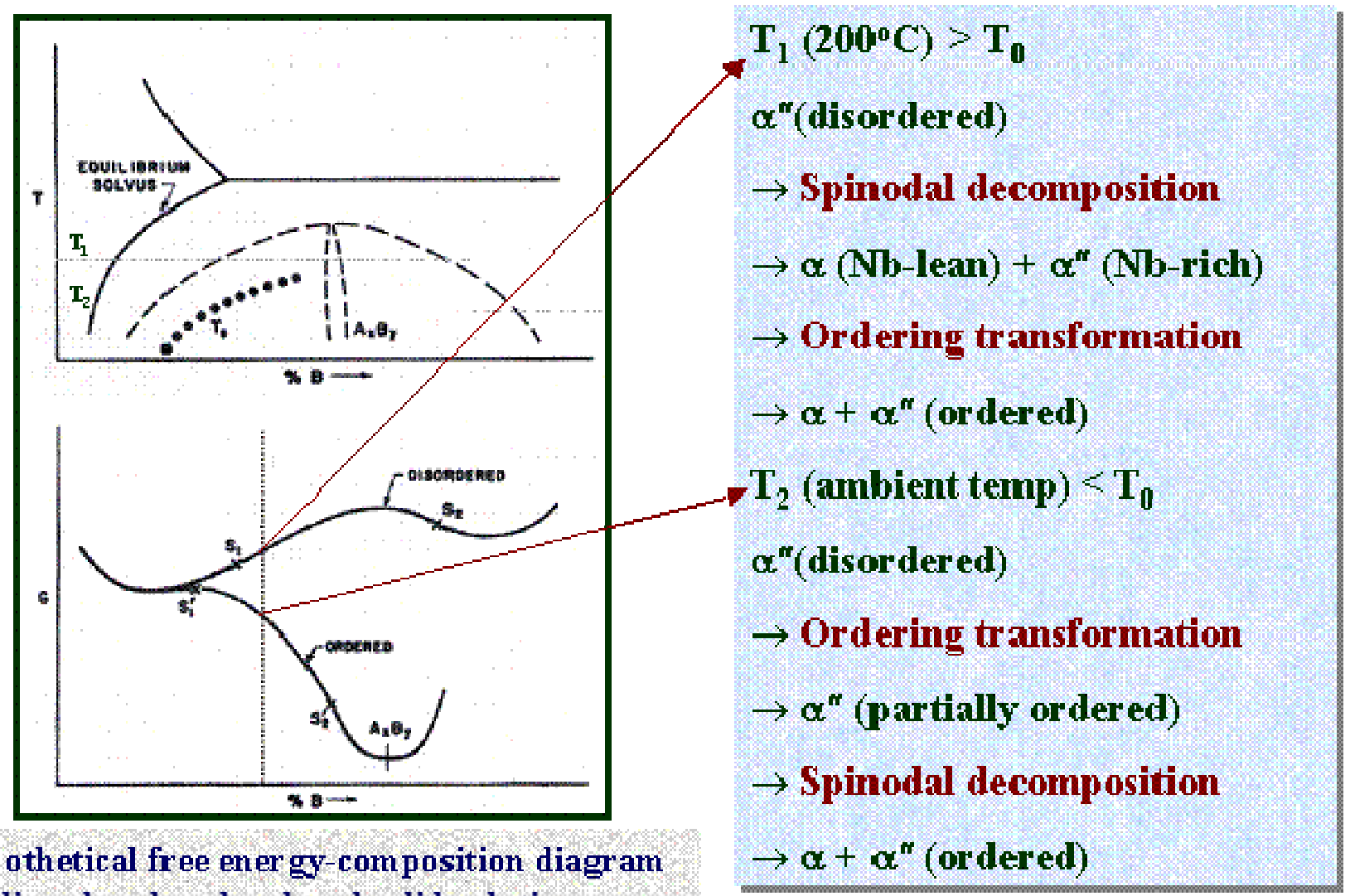

Hyp othetical free energy-composition diagram

for disordered and or dered solid solution.

Fig. 11. Proposed low-temperature aging mechanisms and transformation pathways within WQ-U6Nb aged below $200^{\circ} \mathrm{C}$.

\section{Conclusion}

Aging behavior and phase stability of a water-quenched U6Nb alloy artificially aged at $200^{\circ} \mathrm{C}$ for different periods of time (2, 4, 8, and 16 hours) and naturally aged at ambient temperature for 15 years have been investigated. Age hardening/softening phenomenon is observed from the artificially aged samples. The hardness of the artificially aged alloy samples initially increases from HV $190.0 \pm 5.8$ (WQ) to HV $254.8 \pm 12.2$ (8h) and subsequently decreases to HV $237.3 \pm$ 10.0 (16h). The hardening/softening phenomenon can be well rationalized by the occurrence of spinodal decomposition (i.e. the fine-scale of $\mathrm{Nb}$ segregation) within the artificially aged samples. A modulated structure (presumably containing very fine domains of Nb-lean and Nbrich phases) is first found within $\alpha^{\prime \prime}$ (monoclinic) parent phase at a very local region of the sample aged for 2 hours. The wavelength of the modulation $(\sim 3 \mathrm{~nm})$ is determined according to the spacing of satellite spots exited by the [001] modulation around the Bragg peaks. The modulation becomes more pronounced after aging for 8 hours, which results in the increase of hardness to a maximum. Further aging of the alloy causes the coarsening of segregated domains and results in the decrease in hardness. The occurrence of order-disorder transformation is found within the naturally aged alloy based upon the observation of antiphase boundaries (APBs). A new chemically ordered $\alpha^{\prime \prime}$ phase is proposed based upon the comparison between observed and simulated diffraction patterns. 


\section{Acknowledgements}

This work was performed under the auspices of the U. S. Department of Energy by the University of California, Lawrence Livermore National Laboratory under Contract No. W-7405Eng-48. The authors gratefully acknowledge Bob McKoon, Anne Sunwoo, and T. C. Sun for their contribution to the heat treatment of the U6Nb alloy, Cheng Saw and Octavio Cervantes for the X-ray diffraction analysis, Bob Vallier and Vicki Mason-Reed for the microhardness measurement, and Rick Gross and Jessee Welch for the preparation of TEM foils.

\section{References}

1. Vandermeer, R.A., Acta Metall., 28 (1980), p. 383.

2. Eckelmeyer, K.H., Romig, A.D., and Weirick, L.J., Met. Trans. A, 15A (1984), p. 1319.

3. Vandermeer, R.A., Ogle, J.C., and Northcutt, Jr., W.G., Met. Trans. A, 12A (1981), p. 733.

4. Field R.D., Thoma D.J., Dunn, P.S., Brown D.W., Cady. C.M, Pil. Mag. A, 81 (2001), p. 1691.

5. Jackson, R.J., Miley, D. V., Trans. ASM, 61 (1968), p. 336.

6. Beverini, G., Edmonds, D.V., Colloque De Physique, Colloque C8, C8-429.

7. Cahn J.W., Trans. TMS of AIME, 242 (1968), p. 166.

8. Sato K.and Stobbs, W.M., Phil. Mag. A, 69 (1994), 349.

9. Butler E.P. and Thomas, G., Acta Metall., 18 (1970), 347.

10. Zhoa J.C. and Notis, M.R., Acta. Mater., 46 (1998), 4203.

11. J.W. Edington, Practical Electron Microscopy in Materials Science, Van Nostrand Reinhold, New York, 1976.

\section{FY 2004 Publications/Presentations}

"Low-Temperature Aging and Phase Stability of U6Nb," presented at 2003 MRS Fall Meeting (Boston, MA), December 1, 2003.

“Low-Temperature Aging Behavior of U6Nb," presented at JOWOG28 meeting, Y-12 National Security Complex (Oak Ridge TN), May 12, 2003.

“Ambient and $200^{\circ} \mathrm{C}$ Aging of U6Nb Alloy," presented at ESC annual review meeting, LANL, March 23, 2003.

L.M. Hsiung, C. L. Briant, and K.R. Chasse, "Low-Temperature Aging and Phase Stability of U6Nb,” Mat. Res. Symp. Proc. V. 802 (2004), DD1.6.1. 